\title{
Clinical Trial for COVID-19 Vaccine in Specific Population, Hyper-Protectionism and Waiting for Herd Immunity
}

\author{
Viroj Wiwanitkit \\ Adjunct professor Joseph Ayobabalola University, Ikeji-Arakeji, Nigeria. \\ *Corresponding Author: Viroj Wiwanitkit, Adjunct professor Joseph Ayobabalola University, Ikeji- \\ Arakeji, Nigeria.
}

\section{EDITORIAL}

COVID-19 is the present global problem. More than 100 million patients are recorded within few months after WHO declared for COVID-19 pandemic. The newly available COVID-19 vaccine becomes the hope for disease containment. However, it is still no clear cut for the exact clinical efficacy and usefulness of the new vaccines in prevention for COVID-19. Since the vaccines are usually registered in emergency mode, it cannot expect for the complete research data. The lack of complete large control trial study is common. Nevertheless, there is no data on the efficacy among the specific populations such as pediatric and pregnant subjects. Therefore, the new COVID-19 vaccine is not recommended for some specific populations (such as children [1] and pregnant women [2]). With the limitation, it might cause the problem in disease control.

Indeed, an interesting given reasons for no vaccination for some specific population is the mild symptom among the patients in those groups (such as pediatric population). However, the asymptomatic infection can be spread silently and cause the difficulty in disease control [1]. We presently have a hyperprotectionism regarding COVID-19 in many ways such as school closure but we might give a reason for no vaccination for the children on the opposite basis. We have to wait for the trials or not is an interesting question. Also, we can expect herd immunity after a set of vaccination or not has to be closely monitored.

\section{REFERENCES}

[1] Kamidani S, Rostad CA, Anderson EJ.COVID19 vaccine development: a pediatric perspective. CurrOpinPediatr. 2021 Feb 1;33(1):144-151.

[2] Rasmussen SA, Kelley CF, Horton JP, Jamieson DJ. Coronavirus Disease 2019 (COVID-19) Vaccines and Pregnancy: What Obstetricians Need to Know. Obstet Gynecol. 2021 Feb 4. doi: 10.1097/AOG.0000000000004290. Online ahead of print.

[3] Joob S, Ronald M. Asymptomatic COVID-19: an important clinical consideration. Adv Lab Med Int. 2020; 10: 4 - 5.

Citation: Viroj Wiwanitkit, "Clinical Trial for COVID-19 Vaccine in Specific Population, HyperProtectionism and Waiting for Herd Immunity", International Journal of Research Studies in Medical and Health Sciences. 2021; 6(2): 14-14. DOI: https://doi.org/10.22259/ijrsmhs.0602003

Copyright: () 2021 Viroj Wiwanitkit, This is an open-access article distributed under the terms of the Creative Commons Attribution License, which permits unrestricted use, distribution, and reproduction in any medium, provided the original author and source are credited. 